Original Article

\title{
The effects of core muscle release technique on lumbar spine deformation and low back pain
}

\author{
Myounggi Lee, $\mathrm{PT}^{1)}$, Changho Song, KMD²), Younggwan Jo, KMD³), Donghun Ha, KMD ${ }^{4}$, \\ Dongwook Han, PhD, $\left.\mathrm{PT}^{5}\right)^{*}$ \\ 1) Department of Physical Therapy, Woori Spine Hospital, Republic of Korea \\ 2) Department of Oriental Medicine, Busan Gowoonsunhyung Medicine Clinic, Republic of Korea \\ 3) Department of Oriental Medicine, Changwon Gowoonsunhyung Medicine Clinic, Republic of Korea \\ 4) Department of Oriental Medicine, Yangsan Gowoonsunhyung Medicine Clinic, Republic of Korea \\ 5) Department of Physical Therapy, College of Health and Welfare, Silla University: 700 Beon-gil, 140 \\ Baegyang-daero, Sasang-gu, Busan 617-736, Republic of Korea
}

\begin{abstract}
Purpose] The purpose of this study was to examine the effects of the core muscle release technique on correction of lumbar deformation and alleviation of low back pain. [Subjects] Ninety patients diagnosed with lumbar deformation and low back pain participated in this study. [Methods] The participants were divided into three groups according to method of treatment. The first group was treated with the core muscle release technique (CRT), the second group was treated with general exercise, and the third group was treated with electrotherapy. The core muscle release technique group received 50-minute of the core muscle release technique 5 times a week for 2 weeks, and the participants in this group were instructed not to receive any other treatments. After the 2 weeks of treatment, the patients were reexamined. The general exercise group performed Williams flexion exercises and McKenzie extension exercises 5 times a week for 2 weeks. The electrotherapy group was treated by application of electrotherapy with an interferential current therapy machine (TM-301. TOPMED. Seongnam, Republic of Korea) to the abdominal muscles and back muscles of the lumbar region. [Results] The data suggest that the core muscle release technique, general exercise, and electrotherapy all helped to decrease the alignment angle and VAS score. Of these treatment methods, however, the core muscle release technique was the most effective for treatment of lumbar spine deformation and low back pain. [Conclusion] The core muscle release technique was most effective for correction of lumbar spine deformation and pain alleviation.

Key words: Core muscle release technique, Lumbar spine deformation, Low back pain
\end{abstract}

(This article was submitted Dec. 5, 2014, and was accepted Jan. 20, 2015)

\section{INTRODUCTION}

Low back pain occurs most often in the thoracolumbar, lumbar, or lumbosacral region ${ }^{1)}$. Generally, $90 \%$ of patients with acute low back pain go back to work; however, it has long been known that the symptoms and functional limitations recur in many cases ${ }^{2)}$. The major cause is injury or muscle weakness in the soft tissue of the trunk ${ }^{3)}$; it occurs particularly when the recruitment of core muscles performing a role in stabilization of the lumbar region is weak ${ }^{4,5)}$. With regard to this, Cooper et al. ${ }^{6}$ described how atrophy in lumbar deep muscles was aggravated with chronic low back pain. Danneels et al. ${ }^{7)}$ confirmed that paravertebral muscles were partially atrophied in patients with chronic low back pain as demonstrated by computed tomography

*Corresponding author. Dongwook Han (E-mail: dwhan@ silla.ac.kr)

C2015 The Society of Physical Therapy Science. Published by IPEC Inc. This is an open-access article distributed under the terms of the Creative Commons Attribution Non-Commercial No Derivatives (by-ncnd) License $<$ http://creativecommons.org/licenses/by-nc-nd/3.0/> .
(CT). Kader et al. ${ }^{8)}$ also confirmed with magnetic resonance imaging (MRI) that the multifidus was atrophied in about $80 \%$ of patients with low back pain. In addition, Hodges et al. ${ }^{9)}$ confirmed that in patients with low back pain, recruitment of the transversus abdominis, oblique muscle, rectus abdominis, and erector spinae normally appears in time. The results of these studies show that balanced development of core muscles is a key to prevention of low back pain. For this reason, the current fitness trend has been a change from exercise to eliminate pain by restricting movement by improving muscle strength or stretching ${ }^{10)}$, to exercises that increase core stability ${ }^{11)}$. Recently, the concept of motor control has been integrated into core stability. This is a visual feedback concept, the purpose of which is to encourage the patient to control their own muscle movement by showing the patient ultrasonographic images of their own muscle movement to improve muscle performance ${ }^{12)}$. Along with exercises, joint mobilization or manipulation techniques for vertebral joints have also been used widely to treat spine imbalance $^{13)}$. Nevertheless, core stability exercises have a few limitations. When a patient is not able to keep himself steady due to extreme lumbar deviation or extreme muscle imbalance, inconvenient pretreatment will also be needed. 
Also, unskilled manipulation can cause joint injury as a result of direct stimulation of an injured joint. Therefore, in this study we introduced core muscle therapeutic methods that can build well-proportioned muscles based on two principles: 1) core stability exercises that anyone can perform easily anywhere to build muscle without being constrained by the necessity to use particular tools: and 2) appropriate manipulation for correction of misalignment. In this study, after inducing well-proportioned manipulation of abdominal muscles, paraspinal muscles, the diaphragm, the fascia of the pelvic floor, and thoracolumbar regions using the core muscle release technique (CRT), we examined if lumbar deformation and pain were reduced in patients with low back pain.

\section{SUBJECTS AND METHODS}

Ninety subjects, who were briefed on the experimental procedure, were selected from among those who had once been outpatients of W Hospital in Daejeon, Republic of Korea. Through X-ray and physical examination, the subjects were all found to have deformities in parts of the lumbar spine, and they were all confirmed to be lumbar deformation and low back pain patients by a doctor. This study complied with the ethical principles of the Declaration of Helsinki, and written informed consent was received from each participant. All participants were divided into three groups. Group 1 was treated by CRT, Group 2 was treated by Williams exercise and McKenzie exercise, and Group 3 was treated with electrotherapy. Each group consisted of 15 male and 15 female participants. The average age was 34.2 years in the CRT group, 35.2 years in the common exercise group, and 34.6 years in the electrotherapy group.

Alignment was measured on a radiograph in the anteroposterior view (AP view) of the lumbar spine (L-spine) using the PiviewSTAR STARPACS software (Tsp 03-02, INFINITT. Co., Ltd., Seoul, Republic of Korea). Since the purpose of this study was to determine the degree of lumbar deviation, we marked two points on the L5 spinous process (SP) and L1 SP and then connected the two points. Then we drew two intersecting lines perpendicular to each SP line. The angle between the two intersecting lines was measured for alignment. A visual Analog Scale (VAS) was used to evaluate the degree of pain.

The basic position for CRT was the supine position. With both soles flat on a table and the legs spread as wide as the hip joints, the knee joints were flexed at about $45^{\circ}$ so that the subjects could comfortably lie with their lower backs on the table and rest the upper limbs next to the trunk. The first step was releasing the diaphragm. The therapist put one hand under the thoracolumbar junction, laid the other hand on the brachial region, in the anteroinferior margin of the xiphoid process and the rib; and compressed lightly with both hands. Compression lasted from three to five minutes. Next, compression therapy was conducted for the diaphragm with breathing techniques. For compression of the rectus abdominis and transverses abdominis, the therapist's hands were placed on each side of the umbilicus, and the patient was instructed to inhale deeply through the nose. The therapist compressed the elevated abdomen with both hands while the patient slowly exhaled. This was repeated five times. Therapy on both the internal and external oblique muscles was performed using the same method used for rectus abdominis compression, except with different hand positions. Next, compression of the quadratus lumborum in the posterior region was performed, followed by compression of the erector spinae. To compress the thoracolumbar region through the fascia, compression began at the scapula height. During compression, the patients were instructed to flex their backs slowly so as to bend vertebra-by-vertebra the sections from the thoracic to low-level lumbar spine. Multifidus compression was performed using the same method as for erector spinae compression, with the therapist's hands positioned on the multifidus. Compression of the iliopsoas was performed at the one-third point along the line between the anterior superior iliac spine and the umbilicus along the length of the iliopsoas. Finally, compression of the pelvic floor muscle was performed. One of the therapist's hands was placed on the lower back, and the other was placed on the pubic area or above it; release was induced with light compression $^{14)}$.

The general therapeutic exercise group performed three of the Williams lumbar flexion exercises and three of the McKenzie lumbar extension exercises. For electrotherapy, a hot pack was first applied for 20 minutes to soften the muscles before an interferential current machine (ICT; TM301, TOPMED. Seongnam, Republic of Korea) was used for electrotherapy. Electrical stimulation was applied twice for 15 minutes each in order to trigger strong muscle contractions in the front muscles (the rectus abdominis muscle, oblique abdominal muscle, and transversus abdominis muscle) and back muscles (the erector spinae muscle, quadratus lumborum muscle, and multifidus muscle). To test the homogeneity of the groups, one-way ANOVA was carried out. The paired t-test was conducted to determine changes in lumbar deformation and pain between before and after treatment within each group. One way ANOVA and post hoc analysis with Scheffe's method were also conducted to determine the differences in variations among the three groups. IBM SPSS Statistics for Windows (Version 21.0) was used for statistical analysis; the significance level $(\alpha)$ was 0.05 .

\section{RESULTS}

When the ages of the subjects and homogeneity of the pretreatment variables were checked, no significant differences were found with regard to age, alignment, and VAS. The average age was 34.2 years in the CRT group, 35.2 years in the common exercise group, and 34.6 years in the electrotherapy group (Table 1).

The alignment angle decreased from $6.9^{\circ}$ before treatment to $2.1^{\circ}$ after treatment in the CRT group $(\mathrm{p}<0.05)$. The alignment angle decreased from $6.6^{\circ}$ before treatment to $4.2^{\circ}$ after treatment in the general exercise group $(\mathrm{p}<0.05)$. The alignment angle decreased from $6.5^{\circ}$ before treatment to $5.2^{\circ}$ after treatment in the electrotherapy group $(\mathrm{p}<0.05)$. The VAS score decreased from 8.2 before treatment to 1.4 after treatment in the CRT group $(\mathrm{p}<0.05)$. The VAS score decreased from 8.4 before treatment to 5.8 after treatment in the general exercise group $(\mathrm{p}<0.05)$. The VAS score de- 
Table 1. General characteristics of the subjects (unit)

\begin{tabular}{lccc}
\hline Variables & CRT & Exercise & Electrotherapy \\
\hline Age (years) & $34.2 \pm 11.2^{\mathrm{a}}$ & $35.2 \pm 11.6$ & $34.6 \pm 11.6$ \\
Alignment $\left({ }^{\circ}\right)$ & $6.9 \pm 1.9$ & $6.6 \pm 2.6$ & $6.5 \pm 2.6$ \\
VAS (score) & $8.2 \pm 0.8$ & $8.4 \pm 0.7$ & $8.5 \pm 0.6$ \\
\hline
\end{tabular}

${ }^{a}$ Mean \pm SD. CRT: core muscle release technique

Table 2. The changes in alignment and VAS in the CRT group, exercise group, and electrotherapy group (unit)

\begin{tabular}{llcc}
\hline Variables & Group & $\begin{array}{c}\text { Before } \\
\text { treatment }\end{array}$ & $\begin{array}{c}\text { After } \\
\text { treatment }\end{array}$ \\
\hline \multirow{3}{*}{ Alignment $\left(^{\circ}\right)$} & CRT $^{*}{ }^{*}$ & $6.9 \pm 1.9$ & $2.1 \pm 1.0$ \\
& Exercise $^{*}$ & $6.6 \pm 2.6$ & $4.2 \pm 2.7$ \\
& Electrotherapy $^{*}$ & $6.5 \pm 2.6$ & $5.2 \pm 2.9$ \\
\hline \multirow{3}{*}{ VAS (score) } & CRT $^{*}$ & $8.2 \pm 0.8$ & $1.4 \pm 0.5$ \\
& Exercise $^{*}$ & $8.4 \pm 0.7$ & $5.8 \pm 0.7$ \\
& Electrotherapy $^{*}$ & $8.5 \pm 0.6$ & $7.0 \pm 0.7$ \\
\hline
\end{tabular}

${ }^{a}$ Mean \pm SD. CRT: core muscle release technique

$* \mathrm{p}<0.05$ by paired t-test

Table 3. Comparison of variations between the treatment methods for alignments and VAS (unit)

\begin{tabular}{lccc}
\hline Variables & CRT & Exercise & Electrotherapy \\
\hline Alignment $\left.^{\circ}\right)^{*}$ & $4.8 \pm 1.6^{\mathrm{a}} \mathrm{A}$ & $2.4 \pm 0.7 \mathrm{~B}$ & $1.3 \pm 0.8$ \\
VAS (score) $^{*}$ & $6.8 \pm 0.9 \mathrm{~A}$ & $2.6 \pm 0.5 \mathrm{~B}$ & $1.5 \pm 0.5$ \\
\hline
\end{tabular}

${ }^{a}$ Mean \pm SD. CRT: core muscle release technique

${ }^{*} \mathrm{p}<0.05$ by ANOVA test

A: CRT>exercise \& electrotherapy B: Exercise $>$ electrotherapy

creased from 8.5 before treatment to 7.0 after treatment in the electrotherapy group $(\mathrm{p}<0.05)$ (Table 2$)$.

There were significant differences in the variations of alignment and VAS among the three groups. In the case of alignment, the difference in the variations in the CRT group was the largest, followed by that in the exercise group and then that in the electrotherapy group $(p<0.05)$. In the case of the VAS, the difference in the variations in the CRT group was the largest, followed by that in the exercise group and then that in the electrotherapy group $(\mathrm{p}<0.05)$ (Table 3$)$.

\section{DISCUSSION}

The goal of traditional treatments for low back pain is to enable the functional activities of daily living through strengthening and stretching of the muscles ${ }^{15)}$. However, exercises for muscle strength could actually increase the risk of low back pain ${ }^{11)}$, and the risk may be increased particularly for exercises including full flexion or repetitive torsion of the spine ${ }^{16)}$. Therefore, in recent years interest in the core muscles that control lumbar movement has been rising. Generally, core stability is improved by exercising global and local stability systems in the abdominal and lumbopelvic regions ${ }^{17)}$. The global stability system refers to the larger, superficial muscles around the abdominal and lumbar regions, such as the rectus abdominis, paraspinals, erector spinae, external oblique, and quadratus lumborum muscles ${ }^{18,19)}$. The local stability system refers to the deep intrinsic muscles of the abdominal wall, such as the transversus abdominis, multifidus, internal oblique, and pelvic floor muscles. These muscles are associated with the segmental stability of the lumbar spine during gross whole body movements in which postural adjustments are required ${ }^{11,17-19)}$. Various study results show that core stability exercise is more effective than general fitness exercise ${ }^{20,21)}$. However, even though coordinated contraction of superficial and deep core muscles is needed for more effective core stability exercise ${ }^{22)}$, only local stability exercises, i.e., exercise for the transversus abdominis and multifidus, have been emphasized ${ }^{23)}$. Therefore, studies of core stability training considering the synergy effect of the two systems recently came to the fore ${ }^{17}$. The core muscle approach in this study involves a therapeutic program considering the global stability and local stability systems. The CRT performed in this study involves a therapeutic core muscle technique for the global and local stability systems. One of the essential elements of CRT is respiration. As the diaphragm contracts, intra-abdominal pressure increases and provides spinal stability ${ }^{24)}$. A recent study showed that patients with sacroiliac joint pain had injuries in the diaphragm and recruitment of the pelvic floor ${ }^{25}$. It has been also reported that diaphragmatic dysfunction intensifies the compression on the spine ${ }^{26)}$. Therefore, breathing techniques are considered an important factor in core stability exercises ${ }^{22}$. It has been known that the pelvic floor muscle coordinating with the transverses abdominis during forced expiration also contributes to stability of the lumbar spine ${ }^{24)}$. In the CRT in this study, the patient was allowed to drawing-in for muscle strength exercises of the diaphragm, pelvic floor muscles, and transverse abdominis, and multifidus muscles during compression. The key principle of CRT is to relearn proper movements of the core muscles. Since lack of coordination of the core muscles causes a decrease in efficiency and a compensation pattern that lead to hypertonus and overuse injury, motor relearning is more important than muscle strength exercise ${ }^{11)}$. CRT controls unbalanced muscle tone and smoothly induces coordinated contraction when the body moves. Particularly because muscle tone control for both sides induces proper movement, CRT can be effective for relearning proper movements. Because inhalation increases feed-forward activation of the transversus abdominis prior to body movement ${ }^{27)}$, relearning in recruitment of the transversus abdominis is induced by respiratory therapy, and the results in an increase in the stability of the lumbar region.

Therefore, since CRT controls the stretching and tone of the core muscles, increases flexibility, induces smooth movement of joints, and improves the coordination of core muscles through relearning, it is very effective for correction of deformation and pain alleviation. In this study, the results showed that deformation decreased and pain was alleviated after 2 weeks of treatment. So, when CRT is applied along with core stability exercise, it is expected to ease the financial burden on patients receiving treatment for lumbar spine deformation and for alleviation of pain by reducing the duration and cost of treatment compared with core stability exercise alone, and compared with surgical intervention. 


\section{REFERENCES}

1) Fordyce WE, Brockway JA, Bergman JA, et al.: Acute back pain: a controlgroup comparison of behavioral vs traditional management methods. J Behav Med, 1986, 9: 127-140. [Medline] [CrossRef]

2) Ehrlich GE: Back pain. J Rheumatol Suppl, 2003, 67: 26-31. [Medline]

3) Graves JE, Pollock ML, Foster D, et al.: Effect of training frequency and specificity on isometric lumbar extension strength. Spine, 1990, 15: 504 509. [Medline] [CrossRef]

4) Arokoski JP, Valta T, Kankaanpää M, et al.: Activation of lumbar paraspinal and abdominal muscles during therapeutic exercises in chronic low back pain patients. Arch Phys Med Rehabil, 2004, 85: 823-832. [Medline] [CrossRef]

5) Newcomer KL, Jacobson TD, Gabriel DA, et al.: Muscle activation patterns in subjects with and without low back pain. Arch Phys Med Rehabil 2002, 83: 816-821. [Medline] [CrossRef]

6) Cooper RG, St Clair Forbes W, Jayson MI: Radiographic demonstration of paraspinal muscle wasting in patients with chronic low back pain. $\mathrm{Br}$ Rheumatol, 1992, 31: 389-394. [Medline] [CrossRef]

7) Danneels LA, Vanderstraeten GG, Cambier DC, et al.: Effects of three different training modalities on the cross sectional area of the lumbar multifidus muscle in patients with chronic low back pain. Br J Sports Med, 2001, 35: 186-191. [Medline] [CrossRef]

8) Kader DF, Wardlaw D, Smith FW: Correlation between the MRI changes in the lumbar multifidus muscles and leg pain. Clin Radiol, 2000, 55: 145149. [Medline] [CrossRef]

9) Hodges PW, Richardson CA: Delayed postural contraction of transversus abdominis in low back pain associated with movement of the lower limb. J Spinal Disord, 1998, 11: 46-56. [Medline] [CrossRef]

10) Klaber Moffett J, Frost H: Back to fitness programme. The manual for physiotherapists to set up the classes. Physiotherapy, 2000, 86: 295-305. [CrossRef]

11) Akuthota V, Ferreiro A, Moore T, et al.: Core stability exercise principles Curr Sports Med Rep, 2008, 7: 39-44. [Medline] [CrossRef]

12) Teyhen DS, Miltenberger CE, Deiters HM, et al.: The use of ultrasound imaging of the abdominal drawing-in maneuver in subjects with low back pain. J Orthop Sports Phys Ther, 2005, 35: 346-355. [Medline] [CrossRef]

13) Maitland G, Hengeveld E, Banks K, et al.: Maitland's vertebral manipulation. Oxford: Butterworth Heinemann, 2001.
14) Lee MG, Hwang JS, Seo BD, et al.: The effects of the core muscle release technique on scoliosis. J Phys Ther Sci, 2013, 25: 445-448. [CrossRef]

15) Ferreira ML, Ferreira PH, Latimer J, et al.: Comparison of general exercise, motor control exercise and spinal manipulative therapy for chronic low back pain: a randomized trial. Pain, 2007, 131: 31-37. [Medline] [CrossRef]

16) Farfan HF, Cossette JW, Robertson GH, et al.: The effects of torsion on the lumbar intervertebral joints: the role of torsion in the production of disc degeneration. J Bone Joint Surg Am, 1970, 52: 468-497. [Medline]

17) Marshall PW, Murphy BA: Core stability exercises on and off a Swiss ball. Arch Phys Med Rehabil, 2005, 86: 242-249. [Medline] [CrossRef]

18) McGill SM: Low back stability: from formal description to issues for performance and rehabilitation. Exerc Sport Sci Rev, 2001, 29: 26-31. [Medline] [CrossRef]

19) Behm DG, Anderson K, Curnew RS: Muscle force and activation unde stable and unstable conditions. J Strength Cond Res, 2002, 16: 416-422. [Medline]

20) Fredericson M, Moore T: Muscular balance, core stability, and injury prevention for middle- and long-distance runners. Phys Med Rehabil Clin N Am, 2005, 16: 669-689. [Medline] [CrossRef]

21) Koumantakis GA, Watson PJ, Oldham JA: Supplementation of general endurance exercise with stabilisation training versus general exercise only Physiological and functional outcomes of a randomised controlled trial of patients with recurrent low back pain. Clin Biomech (Bristol, Avon), 2005 , 20: 474-482. [Medline] [CrossRef]

22) Akuthota V, Nadler SF: Core strengthening. Arch Phys Med Rehabil, 2004, 85: S86-S92. [Medline] [CrossRef]

23) Richardson CA, Jull GA: Muscle control-pain control. What exercises would you prescribe? Man Ther, 1995, 1: 2-10. [Medline] [CrossRef]

24) Sapsford R: Explanation of medical terminology. Neurourol Urodyn, 2000, 19: 633. [Medline] [CrossRef]

25) O'Sullivan PB, Beales DJ, Beetham JA, et al.: Altered motor control strategies in subjects with sacroiliac joint pain during the active straight-legraise test. Spine, 2002, 27: E1-E8. [Medline] [CrossRef]

26) McGill SM, Sharratt MT, Seguin JP: Loads on spinal tissues during simultaneous lifting and ventilatory challenge. Ergonomics, 1995, 38: 17721792. [Medline] [CrossRef]

27) Hodges P, Richardson C, Jull G: Evaluation of the relationship between laboratory and clinical tests of transversus abdominis function. Physiother Res Int, 1996, 1: 30-40. [Medline] [CrossRef] 